\title{
Epidural cerebrospinal fluid leak: A rare cause of upper limb amyotrophy - A report of two cases
}

Sir,

The clinical syndrome of lower motor neuron dysfunction due to degeneration of the anterior horn cells in the cervicothoracic region has been described in Hirayama disease (HD), amyotrophic lateral sclerosis and progressive muscular atrophy (spinal) variety, spondylotic myelopathy, and spinal cord infarction. ${ }^{[1,2]}$ We report two cases of epidural cerebrospinal fluid (CSF) leak causing typical "snake eye" appearance on magnetic resonance imaging (MRI) and presenting as upper limb amyotrophy.

A 28-year-old male presented with progressive weakness of bilateral upper extremities for 1 year, followed by atrophy of muscles of the distal forearm and hand. He also had postural hypotension. There was no history of trauma. Power in the right upper limb was $4 / 5$ and the left upper limb was $3 / 5$. He had no sensory deficit. Deep tendon reflexes were brisk in bilateral lower limbs. Clinical diagnosis of bilateral asymmetrical HD was made based on clinical and electrophysiological findings.

MRI of the cervical spine was carried out that showed CSF intensity collection extending from C3 to upper dorsal level. Posterior dura was displaced anteriorly by the CSF intensity collection [Figure $1 \mathrm{a}, \mathrm{b}$ and e]. T2 
hyperintensities were noted in the anterior aspect of the cervical spinal cord from C3 to C5 predominantly in the region of anterior horn cells [Figure 1d]. No posterior epidural enhancement was seen on flexion MRI [Figure 1c]. Magnetic resonance myelography revealed CSF intensity collection in the cervicodorsal posterior epidural space and upper cervical posterior paraspinal region [Figure 1f]. A diagnosis of spontaneous epidural CSF leak with anterior horn cell degeneration was made. The patient was referred for epidural blood patch treatment.

A 28-year-old male presented with weakness and gradual loss of muscle bulk of the left hand and distal forearm over a period of 1.5 years. He was referred to us for MRI of the cervical spine, with a clinical diagnosis of HD. The patient had history of trauma. MRI of the cervical spine revealed CSF intensity collection in the posterior and lateral epidural space of lower cervical and upper dorsal level displacing the dura anteriorly and medially. T2 hyperintensity was also noted in the region of anterior horn cells from the level of C3 to C6 [Figure 2a-c]. No flow void or posterior epidural enhancement was seen on flexion MRI [Figure 2d]. The patient had undergone epidural blood patch treatment.

Epidural spinal CSF leak can be caused by spinal lumbar puncture, epidural or spinal anesthesia, surgery, trauma,
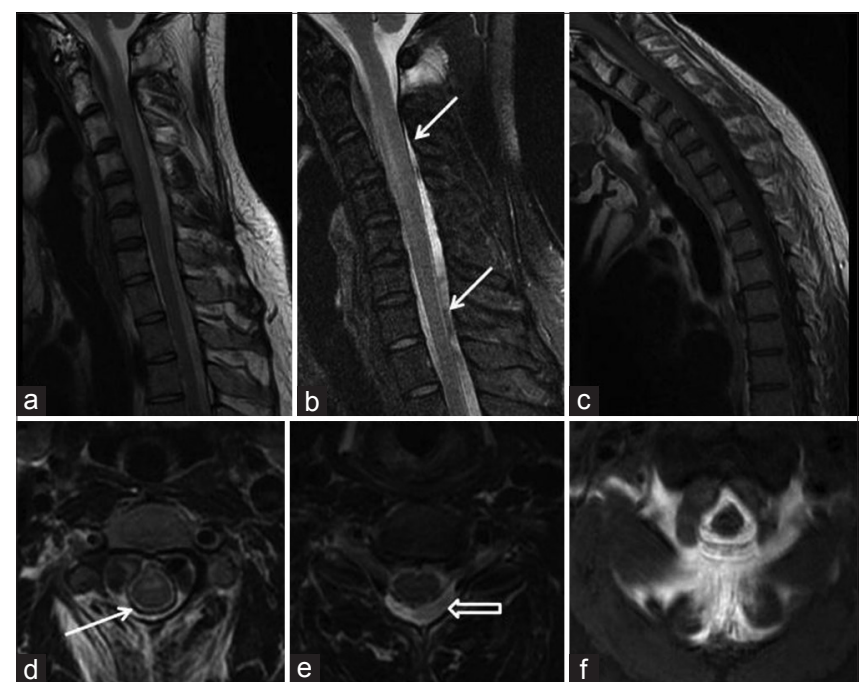

Figure 1: Magnetic resonance imaging of the cervical spine. Sagittal T2-weighted (a), fat saturated T2-weighted imaging (b), showing posterior epidural cerebrospinal fluid intensity collection displacing the dura anteriorly (arrow in b). No epidural enhancement on flexion T1-weighted imaging (c). Axial T2-weighted imaging (d and e) showing anterior horn cell hyperintensity. Dura (white arrow $\mathrm{d}$ ) is seen separating epidural cerebrospinal fluid from subarachnoid space, more clear in (e) (open arrow). Axial magnetic resonance myelography (f) showing cerebrospinal fluid intensity collection in posterior and lateral paraspinal region and rarely osteophytes although a vast majority are spontaneous due to focal dural defect with or without trivial trauma. ${ }^{[3]}$ Chronic epidural CSF leak usually presents with postural headache, nausea, tinnitus, visual and hearing disturbances, diplopia, facial numbness, and tingling of the arms. Intracranial hypotension due to spontaneous CSF leak occasionally associated with cervical myelopathy.

Both of our cases presented with progressive weakness and atrophy of distal muscles of the upper extremities. It is interesting to note that in our cases, chronic posterior epidural CSF collection in this location resulted in anterior horn cell degeneration and a clinical syndrome identical to HD. However, unlike HD, where no epidural abnormality is appreciated in neutral view, we found thin hypointense dura displaced anteriorly by the posterior epidural CSF. No epidural enhancement or abnormal flow void noted in flexion MRI. We suggest chronic dynamic compression of the posterior epidural fluid over the spinal cord while flexion can possibly cause ischemia in the anterior spinal artery territory and subsequent degeneration of anterior horn cells as they are more susceptible to ischemia. This may indirectly support the dynamic chronic epidural compression theory as regards the pathogenesis in HD.

Supportive measures and medical therapy are advised when the patient is less symptomatic. Definitive treatment is to seal the site of the leak, either by epidural blood patch or by surgical repair in refractory cases. ${ }^{[4]}$

The "snake eye" sign on MRI may be seen in many conditions with anterior horn cell loss. Findings on
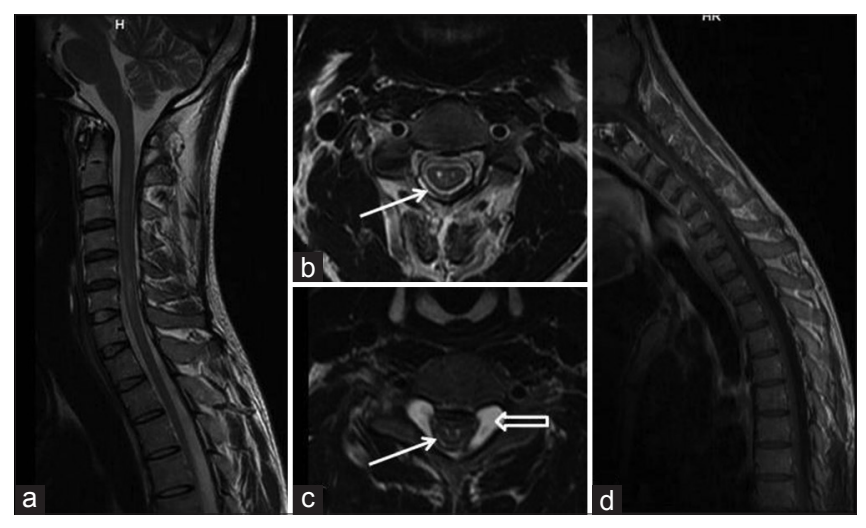

Figure 2: Magnetic resonance imaging of the cervical spine. (a) Sagittal T2-weighted imaging showind hyperintensity in the cervical spinal cord. Axial T2-weighted images ( $b$ and $c$ ) reveal anterior horn cell hyperintensity and the snake eye sign in the cervical spinal cord, dura is seen as thin hypointense line around the spinal cord (arrow) and cerebrospinal fluid intensity outside the dura (open arrow). No epidural enhancement in postcontrast T1-weighted imaging on flexion (d) 
dynamic flexion MRI help correctly differentiating HD from other conditions. Our report also highlights chronic cervical epidural CSF leak as a cause of the upper limb amyotrophy.

\section{Acknowledgment}

We would like to thank the Department of Neurology and Neurosurgery for patient management.

\section{Financial support and sponsorship}

Nil.

\section{Conflicts of interest}

There are no conflicts of interest.

Rajendra V. Phadke, Suprava Naik, Ramesh Muthu, Gurucharan S. Shetty, Vivek Singh, Sunil Kumar

Department of Radiodiagnosis, Sanjay Gandhi Post Graduate Institute of Medical Sciences, Lucknow, Uttar Pradesh, India

Address for correspondence: Dr. Suprava Naik,

Department of Radiodiagnosis, Sanjay Gandhi Post Graduate Institute of Medical Sciences, Raebareli Road, Lucknow - 226014 , Uttar Pradesh, India.

E-mail: drsuprava.rd@gmail.com

\section{References}

1. Gotkine M, Abraham A, Drory VE, Argov Z, Gomori JM, Blumen SC.
Dynamic MRI testing of the cervical spine has prognostic significance in patients with progressive upper-limb distal weakness and atrophy. J Neurol Sci 2014;345:168-71.

2. Lebouteux MV, Franques J, Guillevin R, Delmont E, Lenglet T, Bede P, et al. Revisiting the spectrum of lower motor neuron diseases with snake eyes appearance on magnetic resonance imaging. Eur J Neurol 2014;21:1233-41.

3. Hung LC, Hsu YC. Spontaneous intracranial hypotension resulting from a thoracic osteophyte. J Clin Neurosci 2015;22:1054-6.

4. Rai A, Rosen C, Carpenter J, Miele V. Epidural blood patch at C2: Diagnosis and treatment of spontaneous intracranial hypotension. AJNR Am J Neuroradiol 2005;26:2663-6.

This is an open access article distributed under the terms of the Creative Commons Attribution-NonCommercial-ShareAlike 3.0 License, which allows others to remix, tweak, and build upon the work non-commercially, as long as the author is credited and the new creations are licensed under the identical terms.

\begin{tabular}{|l|l|}
\hline \multicolumn{2}{|c|}{ Access this article online } \\
\hline Quick Response Code: & Website: \\
\hline & www.ruralneuropractice.com \\
\cline { 2 - 3 } & \\
\hline
\end{tabular}

How to cite this article: Phadke RV, Naik S, Muthu R, Shetty GS, Singh V, Kumar S. Epidural cerebrospinal fluid leak: A rare cause of upper limb amyotrophy - A report of two cases. J Neurosci Rural Pract 2016;7:608-10. 